\title{
Factors influencing the adoption of evidence-based principles in nursing education: A J ordanian perspective
}

\author{
Lourance Abdel Razzaq Al Hadid ${ }^{1}$, Marwa A. Al Barmawi ${ }^{2}$ \\ 1. Department of Basic Nursing- Isra University, Jordan. 2. Faculty of Nursing, Alzaytoonah University, J ordan.
}

Correspondence: Lourance A. Al Hadid. Address: Airport Highway, P.O. Box 22, 33, Amman 11622 Jordan. Telephone: 96-279-824-8227. E-mail address: lourans71@hotmail.com

Received: November 7, 2011

Accepted: December 19, 2011 Published: May 1, 2012

DOI : $10.5430 /$ jnep.v2n2p71

URL: http://dx.doi.org/10.5430/jnep.v2n2p71

\begin{abstract}
Objective: Adopting principles of evidence-based in nursing education assists nursing graduates to improve their practice. However, there are factors influencing this adoption. Nurse educators need to identify these factors so that the educational plans based on evidence-based principles can be made. This study aimed to identify the perceived factors influencing adopting evidence-based principles in nursing education among nurse educators in Jordanian Universities.

Methods: A descriptive, cross-section research design was used on a convenience, purposive sample of 85 nurse educators teaching in one of ten Jordanian Universities. Evidence-Based Nursing Education Questionnaire items were derived following a four-step approach; extensive literature review; thematic analysis of literature; expert opinion in the questionnaire items; and the psychometric testing of the questionnaire.

Results: Factors that influence the adoption of evidence-based principles in nursing education programs are: knowledge in educational principles, finding and reviewing evidence, faculty practices, change in education strategies/practices, and finding and judging evidence.

Conclusion: Addressing the factors found in this study increases the awareness of experts to develop strategies that promote the use of evidence-based principles, and increase the probability of faculty adopting them in nursing education.
\end{abstract}

\section{Key words}

Evidence-based, Nursing education, Factors

\section{I ntroduction}

Evidence-based practice (EBP) has been recognized as a necessity to nursing practice to promote excellence in health care during the last two decades ${ }^{[1]}$. The common assumption is that undergraduate education prepares nurses to use principles of evidence-based, especially after graduation ${ }^{[2]}$. This, however, has not been the case in many nursing programs around the world ${ }^{[3]}$. Factors influencing adopting evidence-based principles in nursing programs have not been fully addressed in literature. The Jordanian programs are no exception to this. Therefore, assessing these factors is crucial to facilitate this adoption in nursing education. This study aimed to identify the perceived factors influencing adopting evidence-based principles in nursing education among nurse educators in Jordanian Universities. 


\section{Evidence-based and nursing education}

Emerging from evidence-based medicine, EBP in nursing finds its answers in the recommendations and findings of research-based literature as primary source of information ${ }^{[4]}$.Such approach keeps nursing programs viable and responsive to the political, professional and societal requirements, all of which are driving forces directing the nursing's, as well as the other health professions', present and future needs ${ }^{[5]}$. These include, but not exclusive to, budgetary cuts, standardized care, change in the goals of health care, and quality patient outcome. Nursing programs need EBP to meet those requirements in order to be more responsive to any change within the community and the health care system.

Although limited in its application, EBP in nursing has been strongly presented in the agendas of many professional organizations as an undergraduate requirement in countries, like the USA and Canada ${ }^{[6,7]}$. Among these is the Jordanian Nursing Council (JNC), which emphasizes the adoption of EBP as one crucial component of nursing practice and education ${ }^{[8]}$. The JNC has put forward the futuristic requirements of quality nursing education; yet, it did not explain or recommend steps for this process. It also did not include the adoption of evidence-based principles in education within the process of accrediting nursing programs. Further, decisions of implementing EBP in these programs have not been made explicit to encompass the discourse of strategies of innovative nature to enhance critical thinking and decision making skills among students. While many nursing experts in Jordan emphasize the need to adopt EBP, factors delaying the discourse of EBP in nursing education represent an area of extremely limited knowledge. It is believed that adopting evidence-based in nursing education commences in the undergraduate preparation. It is then emphasized in the graduate programs, which provide the skills required to find, analyze and, later, synthesize best evidence for practice ${ }^{[9]}$. Therefore, assessing factors influencing the adoption of EBP in nursing programs, which graduate future nurses, is crucial to prepare nursing graduates to adopt and implement these principles in their work.

Despite the plethora of literature on what evidence-based nursing is and is not, EBP in nursing education is still struggling and has not been addressed adequately. Many researchers identified factors influencing the adoption of EBP in nursing practice $^{[1,10]}$, which include insufficient educators' skills and time to find research studies, inadequate knowledge on how to evaluate research findings, and lack of organizational support. Reasons reported in literature to influence adopting EBP in nursing education include lack of adequate understanding of technologies associated with the teaching strategies promoting EBP such as the use of human simulation in the nursing laboratories ${ }^{[11]}$, and lack of consensus on the best strategies, material, time and level of students to engage in $\mathrm{EBP}^{[12,13]}$. Other reasons are related to the teaching process, especially in undergraduate education, which focuses mainly on the process of deducting evidence from research rather than conducting research ${ }^{[14,15]}$ abandoning an essential component of EBP. Nursing programs have different elements determining its scope that differ from the clinical settings. So, there remain few unanswered questions on the factors influencing adopting evidence-based principles in nursing programs.

\section{Methods}

\subsection{Design}

A descriptive, cross-sectional research design was used in this study.

\subsection{Sample}

A convenience, non-probability, purposive sample of 180 nurse educators from 10 Jordanian Universities received the study questionnaire. Only 85 (47\%) completed and returned the questionnaire. All educators were teaching in 4-year nursing programs, which graduate baccalaureate degree general nurses. 


\subsection{I nstrument}

Evidence-based education questionnaire (EBEQ) has been developed and validated to measure the factors influencing the adoption of evidence-based principles in nursing education ${ }^{[16]}$. It has two parts: non-identifying demographic data; and the statements that cover EBP in nursing education. Five dimensions were selected in this study to represent nurse educators' perceived factors influencing the adoption of evidence-based principles in their practice. These were 'knowledge in educational principles', 'finding and reviewing evidence', 'ability to find and review the evidence', 'change in education strategies/ practices', and 'faculty practice'. The extent to which the respondents agreed with the presence of each statement was measured ( 0 = strongly disagree, 3 = strongly agree).

The original scale consisted of 54 items. These items were reduced to 24 subsumed within the five factors using principal factor analysis (PCA). This type of factor analysis was used to reduce a large number of items to a smaller number of underlying latent dimensions (factors) ${ }^{[17]}$. The cut-off point of .60 was adopted to confirm that independent variables identified a priori are represented by one of the five factors ${ }^{[18]}$. The overall, as well as individual, items scores were calculated. Further, sampling adequacy, normality, reliability and internal consistency, and descriptive statistics were all measured using SPSS, version 17.

\subsection{Data collection}

The study was approved by the universities' Institutional Review Boards. Consent was implied by returning the completed questionnaires. Participation was entirely voluntary, and the survey was anonymous. Questionnaires were distributed and collected over a 10-week period between October and December 2010. Completed questionnaires were placed at the Dean office, sent by interdepartmental mail or collected anonymously by the investigators.

\section{Results}

\subsection{Demographic profile}

Copies of the questionnaire were distributed on 180 nurse educators, who were teaching in different nursing fields, including adult, maternity, community and psychiatric nursing. The average age of the participants was 37 (range = 24-60). The participants have been working in the teaching role for a mean of 13 years (range $=1$ to 25). Almost half of the participants were doctoral-prepared (49.4\%), and taught full time in both classroom and clinical settings (see Table 1).

Table 1.The demographic characteristics of the participants $(n=85)$

\begin{tabular}{lll}
\hline Variable & & Number (\%) \\
\hline \multirow{2}{*}{ Gender } & Male & $31(36.5 \%)$ \\
& Female & $54(63.5 \%)$ \\
Academic Degree & Baccalaureate in Nursing (Clinical instructors) & $8(9.4 \%)$ \\
& Masters (Clinical and classroom educators) & $35(41.2 \%)$ \\
& PhD (Clinical and classroom educators) & $42(49.4 \%)$ \\
University & Public & $54(63.5 \%)$ \\
& Private & $31(36.5 \%)$ \\
Age & $20-30$ & $24(29 \%)$ \\
& $31-40$ & $35(41 \%)$ \\
& $41-50$ & $21(24 \%)$ \\
& $>51$ & $5(6 \%)$ \\
\hline
\end{tabular}




\subsection{Psychometric properties of the evidence-based education questionnaire}

Cronbach's alpha was calculated for the whole scale to determine internal consistency of the scale (see Table 2). The internal consistency of EBEQ was 0.926; thus, starting factor analysis was reasonable ${ }^{[17]}$. All questionnaire items were submitted to principal factor analysis and the result determined five factors explained by 24 items (from the original 54 items). The factors on the scale correlations ranged from 0.86 to 0.89 . The Spearman-Brown coefficient was 0.82 and Guttman Split Half coefficient was 0.84 , indicating an acceptable item reliability correlation. Split-half reliability measures equivalence, also called parallel forms reliability or internal consistency reliability, was calculated. Spearman-Brown coefficient is a form of split-halves reliability measure. Guttman split-half reliability coefficient is an adaptation of the Spearman-Brown coefficient, but one which does not require equal variances between the two split forms of the questionnaire items. Generally, it is accepted that coefficient value of 0.80 or high and can be considered adequate reliability for both coefficients used here ${ }^{[18]}$.

Table 2. Factors, items and Cronbach’s Alpha values of Evidence-Based Education Questionnaire

\begin{tabular}{|c|c|c|}
\hline Factor & & Statement \\
\hline \multirow{3}{*}{$\begin{array}{l}\text { Knowledge in } \\
\text { educational principles } \\
(\alpha .865)\end{array}$} & K1 & My undergraduate preparation supports evidence-based practice \\
\hline & K2 & My graduate preparation supports evidence-based practice \\
\hline & K3 & Resources are adequate to implement evidence-based practice \\
\hline \multirow{4}{*}{$\begin{array}{l}\text { Finding and reviewing } \\
\text { evidence }(\alpha .840)\end{array}$} & F1 & I feel confident in judging the quality of research reports \\
\hline & F2 & I can understand research reports easily \\
\hline & F3 & I can identify research implications for my own practice \\
\hline & F4 & I know how to find appropriate research reports \\
\hline \multirow{3}{*}{$\begin{array}{l}\text { Faculty practices } \\
(\alpha .894)\end{array}$} & P1 & I get my information from textbooks \\
\hline & P2 & $\begin{array}{l}\text { Lack of consensus recommendations of evidence promotes disparity (lack of agreement) in my } \\
\text { area }\end{array}$ \\
\hline & P3 & Affirmed experiences in clinical practice promote strong evidence for my practice \\
\hline \multirow{6}{*}{$\begin{array}{l}\text { Change in education } \\
\text { strategies/ practices } \\
(\alpha .912)\end{array}$} & $\mathrm{C} 1$ & Empirical evidence is acceptable as mode of change of practice in my faculty \\
\hline & $\mathrm{C} 2$ & My colleagues are supportive of changing practice based on evidence \\
\hline & $\mathrm{C} 3$ & My superiors are supportive of changing practice based on evidence \\
\hline & C4 & My organization supports changing practice based on evidence \\
\hline & $\mathrm{C} 5$ & The continuous education activities support adopting evidence-based principles \\
\hline & C6 & The model adopted in my faculty supports applying evidence-based practice \\
\hline \multirow{8}{*}{$\begin{array}{l}\text { Finding and judging } \\
\text { evidence } \\
(\alpha .942)\end{array}$} & $\mathrm{J} 1$ & I'm familiar with the process of selecting evidence for my practice \\
\hline & $\mathrm{J} 2$ & I can participate in the process of selecting evidence for our practice \\
\hline & J3 & I can determine the quality of evidence \\
\hline & $\mathrm{J} 4$ & I can verify the evidence applicable to my area of practice \\
\hline & J5 & I can judge evidence applicability in my area of practice \\
\hline & J6 & I can deduct evidence through knowledge translation \\
\hline & $\mathrm{J} 7$ & I update my practices by applying reliable and valid research findings \\
\hline & J8 & Implementing evidence-based in education promotes better student quality \\
\hline
\end{tabular}


A principal components analysis using Varimax rotation was performed with five factors (representing 24 items) of the EBEQ. All other items of loading value less than the cut-off point were deleted as these represented weak items (see Table 3). The Cattell's Scree plot test was performed (see Figure 1). At eigenvalue of 1 and more, the first 5 items explained more than $66 \%$ of the total variance. The communality values ranged between 0.584 and 0.86 .

Table 3. Principal factor analysis of the Evidence-Based Education Questionnaire*

\begin{tabular}{|c|c|c|c|c|c|c|c|c|c|}
\hline \multicolumn{2}{|c|}{$\begin{array}{l}\text { Knowledge in } \\
\text { educational } \\
\text { principles }\end{array}$} & \multicolumn{2}{|c|}{$\begin{array}{l}\text { Finding and } \\
\text { reviewing } \\
\text { evidence }\end{array}$} & \multicolumn{2}{|c|}{ Faculty practices } & \multicolumn{2}{|c|}{$\begin{array}{l}\text { Change in education } \\
\text { strategies/practices }\end{array}$} & \multicolumn{2}{|c|}{$\begin{array}{l}\text { Finding and judging } \\
\text { evidence }\end{array}$} \\
\hline Item & Loading & Item & Loading & Item & Loading & Item & Loading & Item & Loading \\
\hline K1 & .669 & $\mathrm{~F} 1$ & .722 & P1 & .877 & C1 & .865 & $\mathrm{~J} 1$ & .864 \\
\hline K2 & .640 & F2 & .670 & $\mathrm{P} 2$ & .774 & $\mathrm{C} 2$ & .789 & $\mathrm{~J} 2$ & .833 \\
\hline \multirow[t]{6}{*}{ K3 } & .624 & F3 & .669 & P3 & .629 & C3 & .746 & $\mathrm{~J} 3$ & .829 \\
\hline & & F4 & .663 & & & $\mathrm{C} 4$ & .736 & $\mathrm{~J} 4$ & .817 \\
\hline & & & & & & $\mathrm{C} 5$ & .731 & J5 & .811 \\
\hline & & & & & & C6 & .642 & J6 & .772 \\
\hline & & & & & & & & $\mathrm{J} 7$ & .653 \\
\hline & & & & & & & & J8 & .601 \\
\hline
\end{tabular}

*Extraction Method: Principal Component Analysis. Rotation Method: Varimax with Kaiser Normalization.

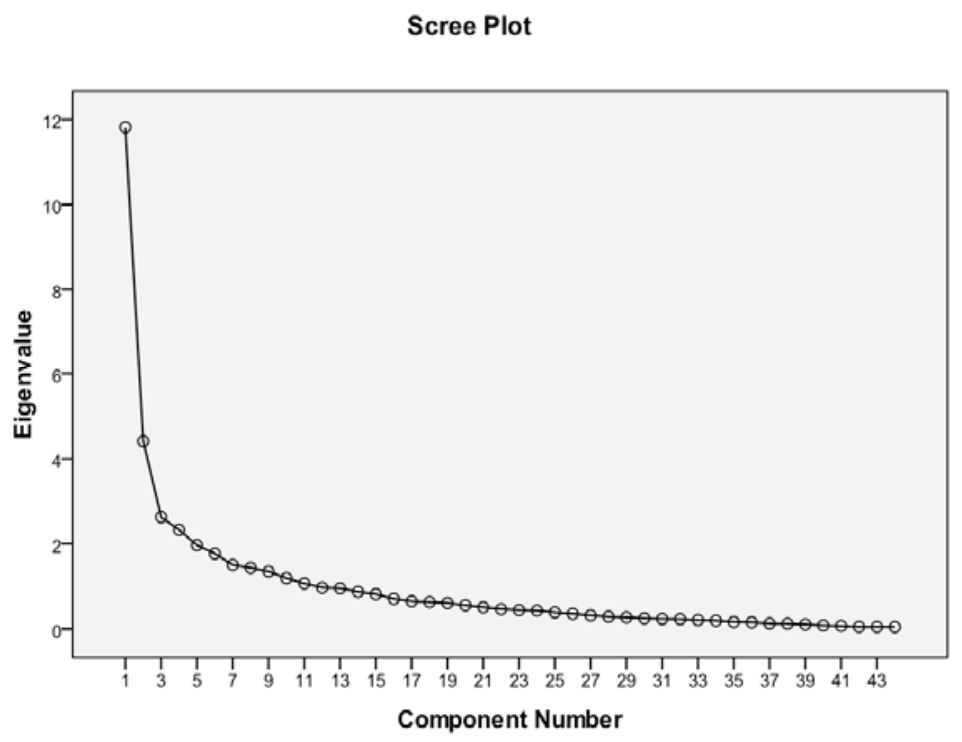

Figure 1. The Scree plot of eigenvalues of scores on Evidence-Based Education Questionnaire

The Q-Q plot in figure 2 shows scores very close to normal line indicating scores close to normal distribution (Skewness= -0.552 , Kurtosis $=1.739$, Komolgrov-Smirnov $=0.066$ [the lower bound of the true significance is 0.200 ]). Normality in this case is accepted; it is often rejected when kurtosis is higher than \pm 2 and/or skewness is higher than \pm 1 indicating that the distribution departs significantly from the normal distribution ${ }^{[18]}$. Furthermore, the total area under the receiver operating characteristic curve was 0.663 ; this value is considered an acceptable one ${ }^{[19]}$. 


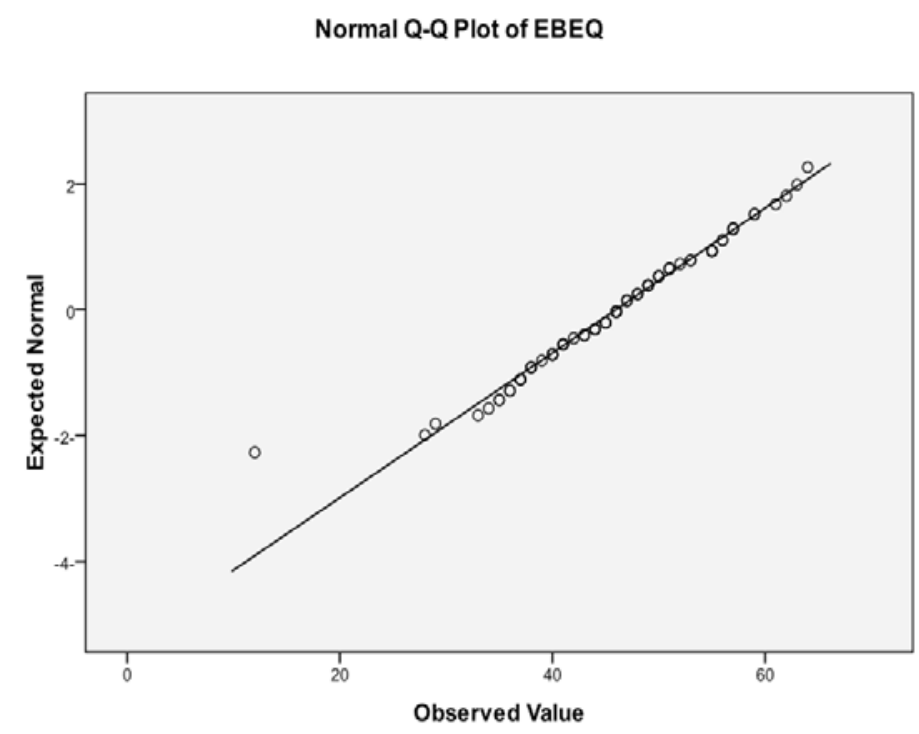

Figure 2. Q-Q probability plot of the participants' scores on the EBEQ

The Kaiser-Meyer-Olkin (KMO) measure of sampling adequacy was 0.874 indicating a high level of inter-correlation among the items. The KMO tests whether the partial correlations among variables are small. Sampling adequacy predicts if data are likely to factor well based on correlation and partial correlation. It is used to assess which variables to drop from the model because they are too multicollinear ${ }^{[20]}$. Large values for the KMO measure indicated that a factor analysis of the variables was right step to take in the process of validation. This result was consistent with Bartlett's test of sphericity, which showed that the correlations between the items were sufficient to perform factor analysis, approximate Chi-Square of $1147.04, p<0.000$. This finding indicated that the strength of the relationship among variables is strong ${ }^{[20]}$.

\subsection{Study limitations}

This study was limited by a number of factors. First, it was limited by the use of a convenience sample and survey method of data collection. Although the response was lower than the desired rate of at least $65 \%$, the $47 \%$ rate falls within the norm ${ }^{[21]}$. EBEQ is a new instrument and needs further testing. Furthermore, it was not re-tested to add another measure to its reliability. Test-retest is often used to assess the consistency of a measure from one time to another ${ }^{[18]}$. As explained above, Cronbach’s alpha was used to measure internal consistency in this study.

\section{Discussion}

The study aim was met in that five factors influencing adopting evidence-based principles in Jordanian nursing programs were identified using a valid and reliable instrument ${ }^{[16]}$. EBEQ was submitted to principal factor analysis to determine the statements which best represent these factors. This method is used to prove useful in the early stages of an empirical enquiry ${ }^{[17]}$. Factors found to influence the adoption of evidence-based in nursing education programs were: knowledge in educational principles, finding and reviewing evidence, faculty practices, change in education strategies/practices, and finding and judging evidence.

\subsection{Psychometric properties of the questionnaire}

The internal consistency of EBEQ was found to be reasonably high for a new instrument ${ }^{[18]}$. Internal consistency, however, does not provide adequate basis to judge reliability. Experts' opinions have, in fact, been the main source of 
decisions upon which omissions and modification took place; this also determined the face validity for the instrument. Furthermore, construct validity was also assessed to ensure theoretical adequacy of the questionnaire items.

Factor analysis, selecting items of powerful representation, setting a relatively high cut-off value were all carried out to ensure the psychometric properties and validity of the questionnaire ${ }^{[22]}$. The deletion of overlapping items, items of weak representation, and irrelevant items added to the statistically-supported values. All statistical values have then indicated that EBEQ is a valid and reliable instrument. Yet, care has to be taken here because this is a new instrument that has been used only once.

\subsection{Factors influencing adopting evidence-based in nursing education}

Five factors have been identified by the participants. The first is 'knowledge in educational principles', which explored the educator's knowledge in education as a subject of study. Many of the nurse educators are in fact prepared to be researchers and experts in their area of study. They, however, receive limited preparation to be educators ${ }^{[23]}$. Although education is their primary role once joining the faculty, there is still a limited focus on the required preparation to teach crucial concepts to contemporary nursing practice like evidence-based. And that is reflected in the approaches and methods of teaching the educators adopt while teaching. Therefore, it remains difficult to teach students concepts needed to understand and appraise research ${ }^{[14]}$. Leaving students with little, if any, knowledge on what evidence-based is, and how they can become evidence-based practitioners after graduation ${ }^{[24]}$.

The second factor is 'finding and reviewing evidence' from literature. Nurse educators differ in their ability to examine and recognize evidence from literature for practice and education ${ }^{[25]}$. EBP requires individuals to deduct scholarly from literature the best available evidence for practice. Although the majority of educator in this study reported high ability to perform these steps, others said that they have limited ability to do so. This has also been reported by other researchers ${ }^{[23,26]}$. This ability could be improved through adopting team approach in finding, discussing, analyzing and agreeing on evidence.

Collaborative work can also modify 'faculty practices', the third factor. When both students and educators work in teams, their experiences may facilitate their learning about EBP ${ }^{[27]}$. Researchers have reported positive findings when adopting similar approach to promote change in faculty practices from the traditional methods of teaching to EBP, especially in the clinical settings ${ }^{[28]}$. Adopting an educational model that requires educators and students to work hand-in-hand could be one of the methods that promotes collaborative work and improves the adoption of evidence-based principles among both students and their educators.

'Change in education strategies/practices' is the fourth factor which influences adopting EBP in nursing education. It has been linked to the educational culture within any nursing program ${ }^{[29]}$. The most common source of nursing practice and education rely on intuitive practices ${ }^{[30]}$. There is a need to induce a paradigm shift from evidence generators to evidence users that nursing programs would consider as the terminal behaviors for EBP in their graduates ${ }^{[31]}$. This, however, is still very limited in Jordan as no evidence can be found (especially in literature) of this movement. Nursing programs are required to adopt EBP so as to prepare graduates who could work within a health system that is characterized by increased customer needs, limited resources (human and materials), and the continuous budget cuts ${ }^{[32]}$. This might be achieved through developing strategies that meet the needs of each particular program while adapting to the health care system requirement based on evidence from literature.

The fifth factor is 'finding and judging evidence'. Educators often work individually on collecting, devising and judging evidence ${ }^{[30]}$. Although this is a very meticulous process, team approach could promote better scrutiny and highlights issues within evidence. Participants in this study reported moderate to low ability in finding and judging evidence from literature. This might be related to the limited experience with EBP during their graduate study and work as educators. Another element within this factor is the presence of database that provides the educators with up-to-date literature when 
searching. This issue is available only in limited form and number in the Jordanian Universities. So increasing university resources of paper and electronic journals might improve educators' experience in this area and improve their experience in finding and judging evidence from literature.

\section{Conclusion}

The goal of assessing factors influencing the adoption of evidence-based principles in nursing education is to provide a mechanism for faculty members to focus interdisciplinary team research attention on preparing nursing graduates and promoting quality education. A methodical assessment is essential in determining the most applicable and appropriate interventions in order to promote the adoption of EBP. Findings in this study highlighted a number of factors influencing this adoption in the field of nursing education. Addressing these factors may increase the awareness of experts in this field to develop strategies that would promote the use of this model and increase the probability of faculty adopting principles of EBP in their practice.

\section{Acknowledgement}

We would like to thank all dear colleagues in nursing faculties who participated eagerly in this study.

\section{References}

[1] Brown CE, Wickline MA, Ecoff L, Glaser D. Nursing practice, knowledge, attitudes and perceived barriers to evidence-based practice at an academic medical center. Journal of Advanced Nursing. 2009; 65: 371-381. PMid:19040688 http://dx.doi.org/10.1111/j.1365-2648.2008.04878.x

[2] Adib-Hajbaghery M. Evidence-Based Practice: Iranian nurses’ perceptions. Worldviews on Evidence-Based Nursing. 2009; 2: 93-101. PMid:19413583 http://dx.doi.org/10.1111/j.1741-6787.2009.00149.x

[3] Adib-Hajbaghery M. Factors facilitating and inhibiting evidence-based nursing in Iran. Journal of Advanced Nursing. 2007; 58: 566-575. PMid:17442028 http://dx.doi.org/10.1111/j.1365-2648.2007.04253.x

[4] Staffileno BA, Carlson E. Providing direct care nurses research and evidence-based practice information: an essential component of nursing leadership. Journal of Nursing Management. 2010; 18: 84-89. PMid:20465733 http://dx.doi.org/10.1111/j.1365-2834.2009.01048.x

[5] McSherry R, Artley A, Holloran J. Research awareness: an important factor for evidence-based practice? Worldviews on Evidence-Based Nursing. 2006; 3: 103-115. PMid:16965312 http://dx.doi.org/10.1111/j.1741-6787.2006.00059.x

[6] Baumbusch JL, Kirkham SR, Khan KB, McDonald H, Semeniuk P, Tan E, Anderson JM. Pursuing common agendas: a collaborative model for knowledge translation between research and practice in clinical settings. Research in Nursing \& Health. 2008; 31:130-140. http://dx.doi.org/10.1002/nur.20242

[7] Elcoat D. Clinical governance in action; key issues in clinical effectiveness. Professional Nurse. 2000; 18: 822-823.

[8] Jordanian Nursing Council [JNC] [Internet]. 2010 October. Available from: http://www.jnc.gov.jo/english/publications/research\%20priorities.pdf

[9] Balakas K, Sparks L. Teaching research and evidence-based practice using a service-learning approach. Journal of Nursing Education. 2010; 49: 691-695. PMid:20795608 http://dx.doi.org/10.3928/01484834-20100831-07

[10] Fink R, Thompson CJ, Bonnes D. Overcoming barriers and promoting the use of research in practice. Journal of Nursing Administration. 2005; 35: 121-129. http://dx.doi.org/10.1097/00005110-200503000-00005

[11] Hart P, Eaton L, Buckner M, Morrow BN, Barrett DT, Fraser DD, Hooks D, Sharrer RL. Effectiveness of a computer-based educational program on nurses' knowledge, attitude, and skill level related to evidence-based practice. Worldviews on Evidenced-Based Nursing. 2008; 5: 75-84. PMid:18559020 http://dx.doi.org/10.1111/j.1741-6787.2008.00123.x

[12] Kim SC, Brown CE, Field W, Stichler JF. Evidence-based interactive teaching strategy: a controlled study. Journal of Advanced Nursing. 2009; 65: 1218-1227. PMid:19445064 http://dx.doi.org/10.1111/j.1365-2648.2009.04975.x

[13] Mattila LR, Eriksson E. Nursing students learning to utilize nursing research in clinical practice. Nurse Education Today. 2007; 27: 568-576. PMid:17064819 http://dx.doi.org/10.1016/j.nedt.2006.08.018 
[14] Burke LE, Schlenk EA, Sereika SM, Cohen SM, Happ MB, Dorman JS. Developing research competence to support evidence-based practice. Journal of Professional Nursing. 2005; 21: 358-363. PMid:16311231 http://dx.doi.org/10.1016/j.profnurs.2005.10.011

[15] Ciliska D. Educating for evidence-based practice. Journal of Professional Nursing. 2005; 21: 345-350. PMid:16311229 http://dx.doi.org/10.1016/j.profnurs.2005.10.008

[16] Al Hadid L, Abu-Hasheesh M, Al Momani M. Validating a tool that explores factors influencing adopting principles of evidencebased practice in nursing education. Journal of Nursing Education. 2011; 50: 681-687. http://dx.doi.org/10.3928/01484834-20110930-03

[17] Tabachnick BG, Fidell LS. Using Multivariate Statistics. Boston: Pearson/Allyn \& Bacon. 2007.

[18] Nunnally JC, Bernstein I.H. Psychometric Theory (3rd edn). New York: McGraw-Hill. 1994.

[19] Fawcett T. An introduction to ROC analysis. Pattern recognition letters. 2006; 27: 861-874. http://dx.doi.org/10.1016/j.patrec.2005.10.010

[20] Kaiser HF, Rice J. Little Jiffy, Mark IV. Journal of Educational and Psychological Measurement. 1974; 34: $111-117$. http://dx.doi.org/10.1177/001316447403400115

[21] Polit DF, Beck CT. Essentials of nursing research: methods, appraisal, and utilization (6th edn). Philadelphia, PA: Lippincott/Williams \& Wilkins. 2008.

[22] Streiner DL, Norman GR. Health measurement scales. A practical guide to their development and use. Oxford: Oxford University Press. 1999.

[23] Mansour TB, Porter EJ. Edu $\neg$ cators' experience of teaching nursing research to undergraduates. Western Journal of Nursing Research. 2008; 30: 888-904. PMid:18359922 http://dx.doi.org/10.1177/0193945907312975

[24] Oh EG, Kim S, Kim SS, Kim S, Cho EY, Yoo J, et al. Integrating evidence-based practice into RN-to-BSN clinical nursing education. Journal of Nursing Education. 2010; 49: 387-392. PMid:20411864 http://dx.doi.org/10.3928/01484834-20100331-02

[25] Meeker MA, Jones JM, Flanagan NA. Teaching undergraduate nursing research from an evidence-based practice perspective. Journal of Nursing Education. 2008; 47: 376-379. PMid:18751652 http://dx.doi.org/10.3928/01484834-20080801-06

[26] Özdemir L, Akdemir N. Turkish nurses' utilization of research evidence in clinical practice and influencing factors. International Nursing Review. 2009; 56: 319-325. PMid:19702805 http://dx.doi.org/10.1111/j.1466-7657.2009.00707.x

[27] Singleton J, Levin R. Strategies for learning evidence-based practice: critically appraising clinical practice guidelines. Journal of Nursing Education. 2008; 47: 380-383. PMid:18751653 http://dx.doi.org/10.3928/01484834-20080801-07

[28] Burns HK, Foley SM. Building a foundation for an evidence-based approach to practice: teaching basic concepts to undergraduate freshman students. Journal of Professional Nursing. 2005; 21: 351-357. PMid:16311230

http://dx.doi.org/10.1016/j.profnurs.2005.10.001

[29] Missal B, Schafer BK, Halm MA, Schaffer MA. A university and health care organization partnership to prepare nurses for evidence-based practice. Journal of Nursing Education. 2010; 49: 456-461. PMid:20438029 http://dx.doi.org/10.3928/01484834-20100430-06

[30] Melnyk BM. Calling all educators to teach and model evidence-based practice in academic settings. Worldviews on Evidenced-Based Nursing. 2006; 3: 93-94. PMid:16965310 http://dx.doi.org/10.1111/j.1741-6787.2006.00061.x

[31] Fineout-Overholt E, Johnston L. Teaching EBP: a challenge for educators in the 21st century. Worldviews on Evidence-Based Nursing. 2005; 2: 37-39. PMid:17040555 http://dx.doi.org/10.1111/j.1524-475X.2005.04098.x

[32] Brancato V. An innovative clinical practicum to teach evidence-based practice. Nurse Educator. 2006; 31: 195 -199. PMid:16980821 http://dx.doi.org/10.1097/00006223-200609000-00004 